\title{
CALIBRATING SEISMOMETERS BY MEANS OF EARTHQUAKE DATA
}

\author{
R. D. Forester
}

Abstract--Recordings of earthquakes were used to calculate the magnification of ground motion produced by various seismometers. The calculations were based upon the ' $A$ ' values (energy parameters) listed by Gutenberg for seismic waves $P$, $P D$, and $S$. Results of the calibration procedure indicate that the energy content of $P$, PP, and $S$ waves recorded on Benioff instruments increases with increasing wave period. In order to calibrate the horizontal seismometers by use of recorded longitudinal waves, it is necessary to correct for the fact that the amplitudes recorded transverse to the direction of wave propagation are appreciable. The resultant calibrations were accurate enough to be used for a subsequent study of the energy content of seismic waves.

The energy content of seismic waves is commonly studied by ascertaining the ratio of the energy the phase of interest to that of a phase whose energy characteristics are weli known, such as $P$, PP, or S. For some phases, such as SKP, there is no phase suitable for an energy comparison. Eence, the energy content of such phases can be determined only by direct methods.

In order to analyze the energy content of a seismic wave directly, it is necessary to determine we magnifications used at the time the phase was recorded. Frequently, changes in the gain settings of the seismometers are not recorded, for the seismograms are used primarily for studies of travel times rather than energy. Consequently, the only way to determine the magnifications of such seismometers for any period in the past is to make use of their seismograms which have recorded phases whose energy characteristics are well known.

GUTENBERG [1945] has developed an equation for the calculation of earthquake magnitude from measurements of observed amplitude-to-period ratios of seismic body waves

$$
\mathbf{M}=\mathbf{A}+\log |\mathbf{w} / \mathrm{t}|+\mathbf{K}(\mathbf{M}-7) \ldots \ldots \ldots \ldots
$$

A = energy parameter calculated from travel data. A values are listed by GUTENBERG [1945] for different wave types as a function of epicentral distance

w observed ground amplitude, microns

$t=$ wave period, seconds

$\mathbf{K}=$ residual factor used to correct for the slight dependence of $A$ values on magnitude

Substitution of $W / R$ for $w$ into (1), where $W$ is the amplitude recorded on the seismogram and $\mathbb{R}$ is the magnification, and solving for $R$ yields

$$
\log R=A-M+\log |w / t|+K(M-7) \ldots \ldots \ldots
$$

To account for the relative difference in ground sensitivity at variaus saismograph stations, the station ground factor, G, was added to (2)

$$
\log R=A-M+\log |W / t|+K(M-7)+G \ldots \ldots \ldots
$$

Eq. (3) was used to calculate the magnifications of several Pasadena and Huancayo seismomters. Amplitudes and periods were measured for earthquakes of magnitudes ranging from 7.0 to 7.7. The epicentral distance used for P ranged from 30 to $90^{\circ}$; that for PP, from 85 to $130^{\circ}$; and that for $S$, from 30 to $100^{\circ}$. Readings were not taken at epicentral distances where the $A$ values listed by GUTENBERG [1945] changed abruptly. $K$ was set equal to 0.2 . G was set equal to 0.2 for Pasadena and to 0.0 for Huancayo. Earthquake magnitudes were taken from GUTENBERG and MICHTER [1949].

The ratios of the magnifications determined by earthquakes to the magnifications read from reference frequency response curves were computed. Markus Bath determined the absolute 
Table 1--Sensitivity factors

\begin{tabular}{|c|c|c|c|}
\hline \multirow{2}{*}{ Location } & \multirow{2}{*}{ Type of instrument } & Time interval tested & \multirow{2}{*}{$\begin{array}{l}\text { Number of } \\
\text { observations }\end{array}$} \\
\hline & & \begin{tabular}{l|l} 
from & to \\
\end{tabular} & \\
\hline Pasadena & $\begin{array}{l}\text { Short-period Benioff } \\
\text { vertical }\end{array}$ & $\begin{array}{l}\text { Apr. } 1936 \text { - Feb. } 1944 \\
\text { Feb. } 1944 \text { - July } 1946 \\
\text { Aug. } 1946 \text { - July } 1947 \\
\text { July } 1947 \text { - Jan. } 1951\end{array}$ & $\begin{array}{l}55 \\
29 \\
19 \\
54\end{array}$ \\
\hline Pasadena & $\begin{array}{l}\text { Long-period Benioff } \\
\text { vertical }\end{array}$ & June 1938 - Dec. 1950 & 62 \\
\hline Pasadena & $\begin{array}{l}\text { Long-period Benioff } \\
\text { N-S horizontal }\end{array}$ & Feb. 1937 - Dec. 1950 & 46 \\
\hline Pasadena & $\begin{array}{l}\text { Long-period Benioff } \\
\text { E-W horizontal }\end{array}$ & Dec. 1937 - Dec. 1950 & 46 \\
\hline Huancayo & $\begin{array}{l}\text { Long-period Wenner } \\
\text { N-S horizontal }\end{array}$ & Oct. 1932 - Nov. 1942 & 48 \\
\hline Huancayo & $\begin{array}{l}\text { Long-period Wenner } \\
\text { E-W horizontal }\end{array}$ & Oct. 1932 - Nov. 1942 & 44 \\
\hline
\end{tabular}

magnifications of the short and the long-period, Benioff vertical seismometers at Pasadena in 1951. His values served as reference curves for all the short- and the long-period Benioff seismometers to be calibrated, both vertical and horizontal. For the Huancayo instruments, an arbitrary referesct curve based upon the pendulum and galvanometer periods indicated by indicial response tests was used.

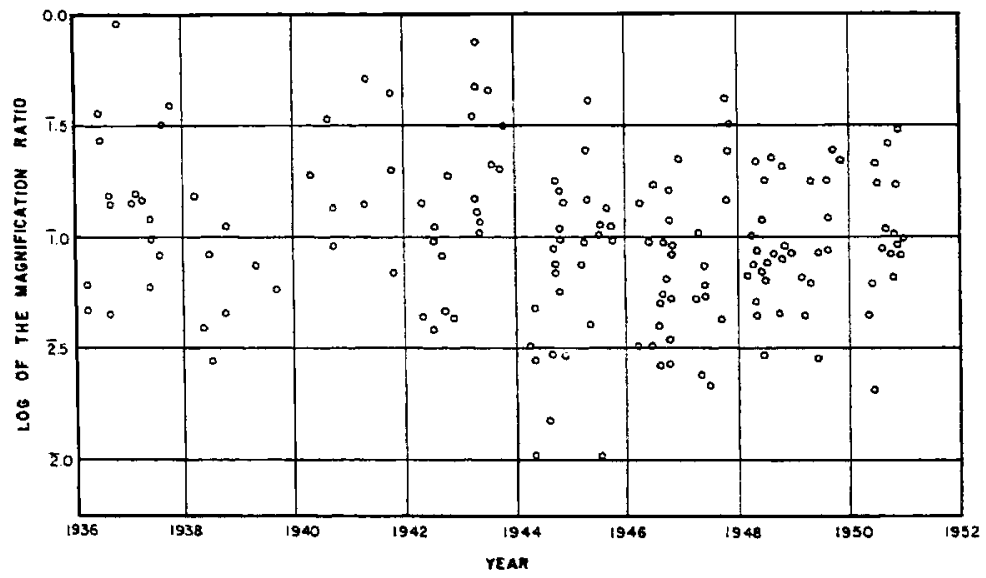

Fig. 1--Sensitivity of the short-period, vertical Benioff seismometer at Pasadena

The logarithms of the magnification ratios were plotted for each instrument on a separate grath The $\log$ ratios were plotted against the dates of the earthquakes examined. Figure 1 shows such 2 plot for the short period, Benioff vertical instrument. The use of logarithms gives a statistically normal distribution of points. The very low values from 1944 to 1948 indicate that the sensitivity was definitely lower during that period.

The mean value of the $\log$ ratios was computed for each period during which the graphs indteats no change in sensitivity. The antilog of this value, designated as the 'sensitivity factor,' appears Table 1, which lists some of the instruments calibrated.

The standard deviation of the $\log$ ratios from their arithmetic mean was generally about 0.3 . This indicates that the standard deviation factor for the sensitivity (see Table 1) was about 2 . For 
urious seismometers

\begin{tabular}{|c|c|c|c|c|c|}
\hline $\begin{array}{l}\text { Standard de- } \\
\text { viation factor }\end{array}$ & $\begin{array}{l}\text { Pendulum } \\
\text { period }\end{array}$ & $\begin{array}{c}\text { Galvanometer } \\
\text { period }\end{array}$ & $\begin{array}{l}\text { Observed } \\
\text { mean period }\end{array}$ & $\begin{array}{c}\text { Sensitivity } \\
\text { factor }\end{array}$ & $\begin{array}{l}\text { Magnification } \\
\text { at mean period }\end{array}$ \\
\hline & $\sec$ & $\sec$ & $\sec$ & & \\
\hline $\begin{array}{l}2.3 \\
2.1 \\
1.8 \\
1.9\end{array}$ & $\begin{array}{l}0.99 ? \\
0.99 ? \\
0.99 ? \\
0.99 ?\end{array}$ & $\begin{array}{l}0.19 ? \\
0.19 ? \\
0.19 ? \\
0.19\end{array}$ & $\begin{array}{l}1.38 \\
1.13 \\
1.33 \\
1.32\end{array}$ & $\begin{array}{l}0.43 \\
0.27 \\
0.20 \\
0.33\end{array}$ & $\begin{array}{l}4000 \pm 25 \text { pct } \\
3500 \pm 30 \text { pct } \\
2000 \pm 30 \text { pct } \\
3300^{\mathrm{a}}(20 \text { pct })\end{array}$ \\
\hline 2.0 & 0.99 & 1.12 & 3.36 & 0.97 & $910^{\mathrm{a}}(20$ pct $)$ \\
\hline 1.8 & $0.99 ?$ & 0.95 & 3.18 & 0.97 & $960 \pm 20$ pct \\
\hline 2.2 & $0.99 ?$ & 0.78 & 3.55 & 1.28 & $1140 \pm 25$ pct \\
\hline 2.0 & 8.5 & 11.8 & 6.25 & 0.89 & $900 \pm 20$ pct \\
\hline 2.0 & 9.3 & 12.8 & 6.27 & 1.00 & $1000 \pm 25 \mathrm{pct}$ \\
\hline
\end{tabular}

Båth's value.

a standard deviation in the $\log$ ratio of 0.3 , the Student's $t$ distribution of statistics indicates that 2t least $30 \mathrm{log}$ ratios must be averaged if there is to be 95 pct confidence that the true mean will wa differ by more than 0.1 from the sample mean, or in other words, 30 readings are necessary to be 95 pct certain that the sensitivity is not in error by more than 25 pct. An abnormally high whe for the standard deviation factor would suggest that the sensitivity had been changed during the time interval tested.

Since the sensitivity for the N-S component was suspected to differ appreciably from that of the $\mathrm{E}-\mathrm{W}$ component for each pair of horizontal instruments, the components were calibrated separately.

Figure 2 shows that the $\log$ ratios increase with an increase of the azimuthal difference between the direction of wave propagation and the seismometer response axis. Hence, the procedure of ditiding the amplitude of a $P$ or a PP wave by the cosine of the azimuthal difference produces overcorrection. Figure 2 indicates that the energy recorded for $P$ and $P P$ is sizable even when the revording instrument is transverse to the direction of wave propagation. This may result from the and that there is SH motion mixed with longitudinal motion or that appreciable energy has been warizontally refracted by lateral discontinuities in the Earth's crust.

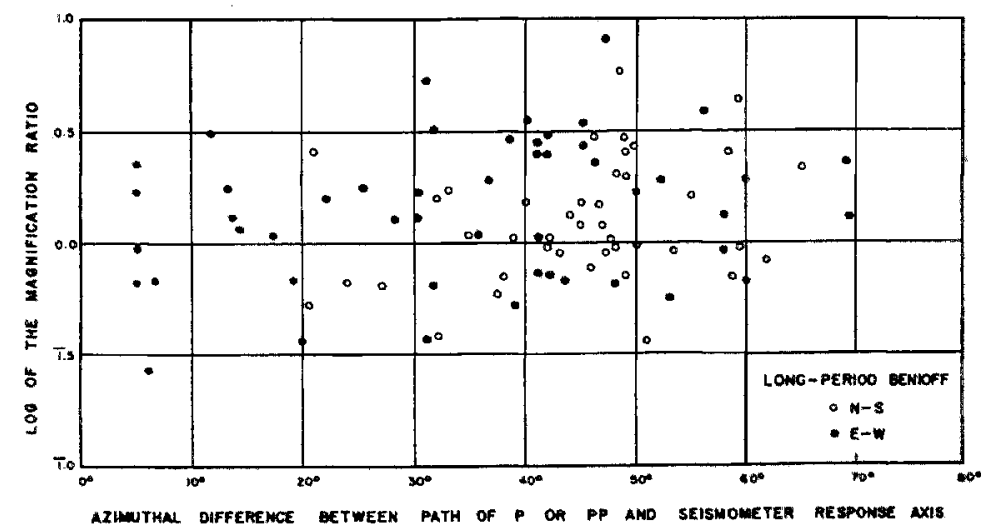

Fig. 2--Sensitivity of long-period horizontal Benioff seismometer 
To eliminate such over-correction, the amplitudes were divided by a parabolic function, 1 $\theta^{2} \mathrm{~K}$, where $\theta$ equals the azimuthal difference, and $\mathrm{K}$ is a constant determined from the ratio of the square root of the energy appearing on an instrument oriented transverse to the direction of prope gation to that appearing on an in-line instrument. Since there were only a few instances where a pair of horizontal instruments were so oriented, it was necessary to extrapolate the values for the recorded energy to what they would have been for such an orientation. The extrapolation is thus tantamount to a rotation of the horizontal instruments. In order to extrapolate, values for $\mathrm{K}$ were Initially assumed, and subsequently refined by successive approximation. Energy values which required more than $30^{\circ}$ of extrapolation were not used, for the ability to refine an assumed value for $\mathbf{K}$ is optimal when the horizontal components are transverse and in-line, and nil when they are oriented at angles of $45^{\circ}$ with respect to the direction of wave propagation.

Since an energy ratio comparison for a pair of horizontal instruments depends upon the sensitivity of the instruments relative to each other, as well as $\mathrm{K}$, the entire calibration procedure had to be repeated until the values determined for the sensitivity ratio and $\mathrm{K}$ remained stationary.

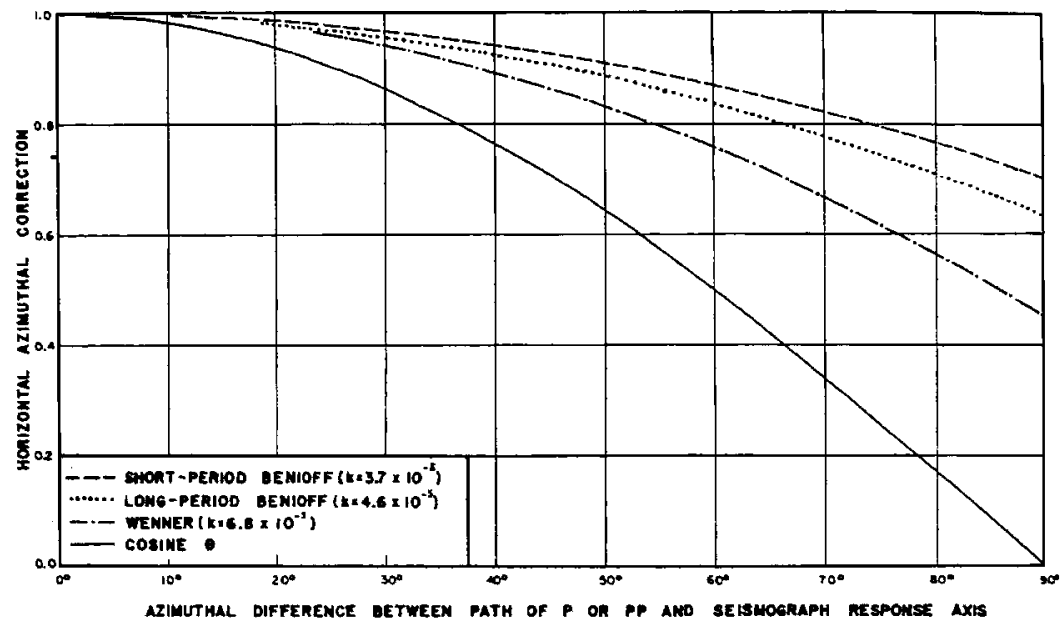

Fig. 3--Relation between azimuthal difference and horizontal azimuthal correction

In Figure 3, the upper three curves are a plot of the horizontal correction factor, $1-\theta^{2} \mathrm{~K}$, where $\mathrm{K}$ serves as a parameter. Each curve indicates what the amplitude of a wave recorded as unity on the in-line component would be for various azimuthal differences. For $\theta=90^{\circ}$, the shortperiod Benioff instrument has an amplitude equal to 0.8 that of its in-line value; the lang-period Benioff, 0.63 ; and the very long-period Wenner, 0.45. This indicates that the longer the periods which determine the instrumental response, the 'purer' is the motion recorded for P and PP.

Since shear waves consist of both SH and SV components, their analysis is more complex than that for longitudinal components. Consequently, shear waves were not used to calibrate the horizontal instruments.

The gain ratios of both the long-and the short-period instruments appeared to be independent of the type of phase used for calibration. This attests the accuracy of the Gutenberg A values for $P, P P$, and $S$ relative to each other.

In Table 1, the arithmetic mean of the periods of the observed waves and the magnification corresponding to the mean period are listed for each instrument. The sensitivity factor for the long-period, vertical instrument is listed as 0.97 and that for the short period, vertical instrument for the period from July, 1947, to January, 1951, as 0.33 . Values of unity would indicate perfect agreement with the reference curves. The long period sensitivity factor agrees with 2 value of unity well within the limits of experimental error. However, the short-period sensitivity factor is much too small to be attributed to experimental error, and probably indicates that less energy was recorded by the short- than by the long-perlod instrument. Accordingly, the A values listed by Gutenberg do not seem to be independent of the wave period. 


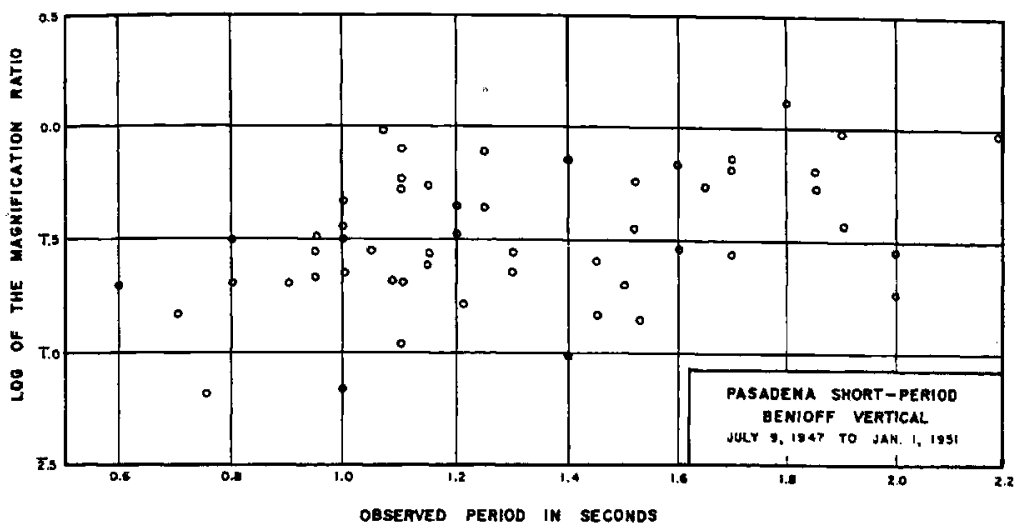

Fig. 4--Relation of magnification ratio to period of phase used

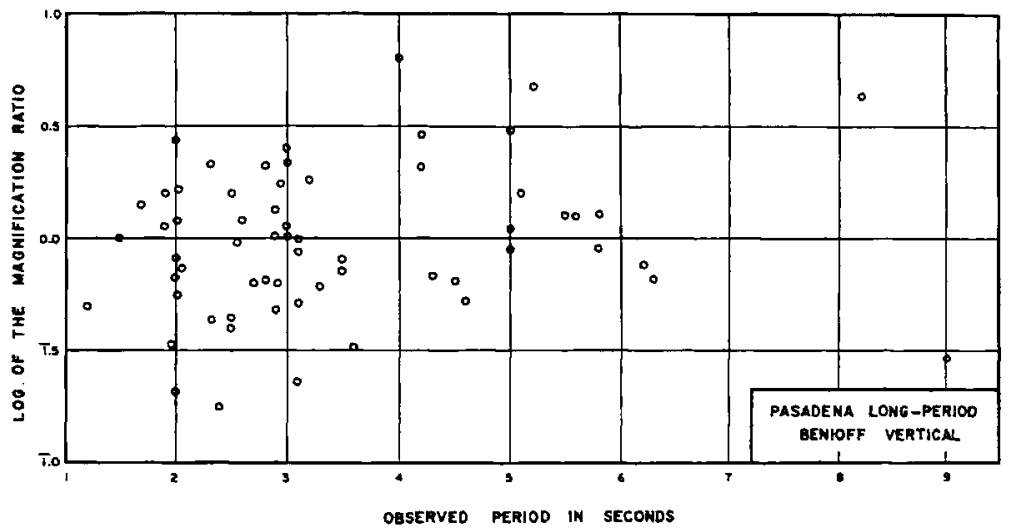

Fig. 5--Relation of magnification ratio to period of phase used

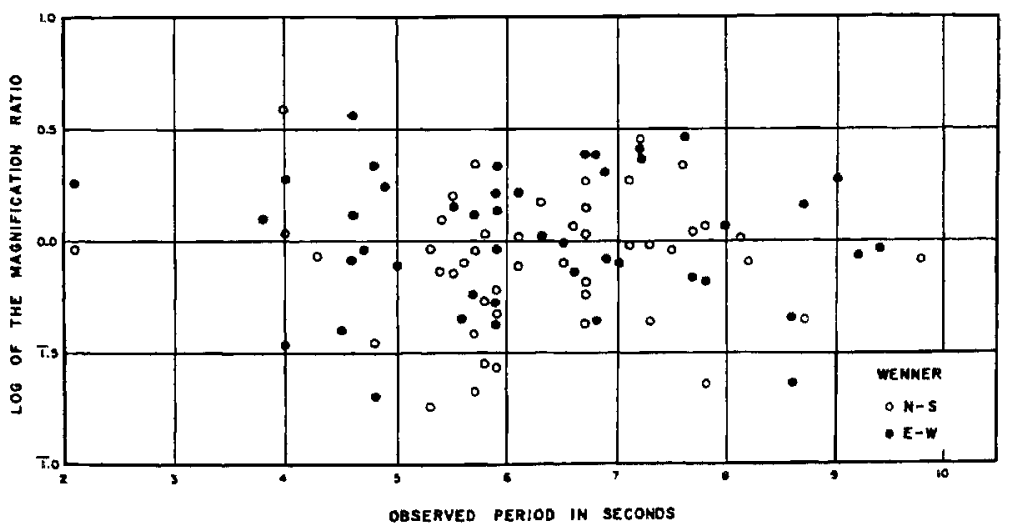

Fig. 6--Relation of magnification ratio to period of phase used

Figures 4,5 , and 6 show plots of the $\log$ of the magnification ratio versus the period of the pase used for calibration. The plots for the Benioff instruments indicate that the value of the log ratio increases with increasing period. The plot for the Wenner instruments is random. The plots suggest that the energy content of $P, P P$, and $S$ increases with period except for waves of periods as long as those recorded on the wenner instruments. 
For the long-period instruments, the magnification of the mean period was determined by multiplying its value on the reference curve by the sensitivity factor. However, because the sensitivity factor of the short-period instrument was too small by a factor of three, the magnification obtained for this instrument was increased by a factor of three.

Complete magnification curves can be determined for each instrument by use of the magntfi. cation of the mean period listed in Table 1 and the response factor for critically damped electro. magnetic seismometers:

$$
\text { Response factor }=\mathrm{T} /\left(1+\mathrm{T}^{2} / \mathrm{T}_{\mathrm{o}}^{2}\right)\left(1+\mathrm{T}^{2} / \mathrm{T}_{\mathrm{g}}^{2}\right) \ldots \ldots \ldots \ldots
$$

$T=$ period of wave motion

$T_{0}=$ period of the pendulum

$T_{\mathrm{g}}=$ period of the galvanometer

Several causes can be advanced to explain the large standard deviation factors associated with the gain ratios listed in Table 1 . Such causes are not independent of each other:

(1) A values are not independent of frequency.

(2) The basic assumptions upon which the magnitude scale depends are approximate empirical relations [see GUTENBERG and RICHTER, 1942; GUTENBERG, 1945].

(3) Energy emanates from the hypocenter of an earthquake asymmetrically with azimuth.

(4) Eq. (4) is derived for steady state solutions; hence, its application to short seismic pulses will introduce significant error.

(5) Sometimes the maximum amplitude within a phase does not signify maximum energy. In Figure 7, a slope of $45^{\circ}$ to the right indicates that energy is constant for waves of constant amplitude, but different frequencies. The slope for the long-period Benioff instrument is close to $45^{\circ}$. Hence, the waves with the largest amplitudes will contain the most energy. The slope for the short-period Benioff instrument is much steeper than $45^{\circ}$. For waves of the same amplitude, those with the longer periods will contain more energy. The slope for the Huancayo instrument reverses from the left to the right as the period increases. For waves of the same amplitude, those with the shorter period will contain more energy, except for waves of very lang periods.

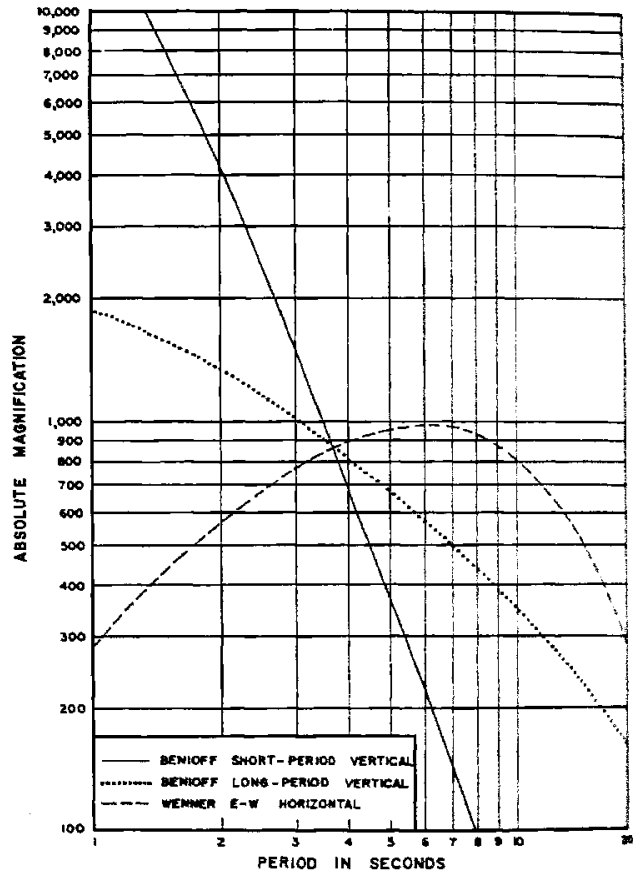

Fig. 7--Relationship of magnification and period

\section{References}

GUTENBERG, B., Energy ratio of reflected and refracted seismic waves, Bul. Seis. Soc. Amer., v. 34 , no. 2, pp. 85-102, 1944.

GUTENBERG, B., Amplitudes of P, PP, and $S$ and magnitudes of shallow earthquakes, Bul. Seis. Soc. Amer., v. 35, no. 2, pp. 57-69, 1945.

GUTENBERG, B., and C. F. RICHTER, Earthquake magnitude, intensity, energy, and acceleration, Bul. Seis. Soc. Amer., v. 32, no. 3, pp. 163-191, 1942.

GUTENBERG, B., and C. F. RICHTER, Seismicity of the Earth and associated phenomena, Priacetst Univ. Press, 1949.

California Institute of Technology

Division of the Geological Sciences

Pasadena, California

(Communicated manuscript received July 29, 1954, and, as revised, July 5, 1955; open for formal discussion until March 1, 1956.) 